\title{
Empleo e intercambio social en México
}

\author{
Mercedes González de la Rocha, ${ }^{*}$ Martha Moreno Pérez, ${ }^{* *}$ \\ Inés Escobar***
}

Perfiles Latinoamericanos, 24(47)

2016 | pp. 225-258

DOI: $10.18504 / \mathrm{pl} 2447-012-2016$

\section{Resumen}

Este artículo indaga la relación entre el empleo y el grado de confianza en acceder a favores/ayuda con datos de la Encuesta Nacional de Ingresos y Gastos de los Hogares de 2008, 2010 y 2012. Los resultados indican que el empleo estable y protegido se vincula a grados más elevados de confianza y que la precariedad laboral se asocia a una menor confianza en el acceso al intercambio de favores. El dinero y el tiempo son recursos clave para participar en dos distintos circuitos de ayuda: el de los favores monetarios y el de las permutas de ayuda en forma de cuidados.

\begin{abstract}
Based on ENIGH 2008, 2010, and 2012 data, this article examines the relation between employment and people's trust in their ability to access support networks in times of need. The results reveal that stable and protected employment is linked to higher levels of trust while precarious work is associated with a lower degree of belief in one's ability to access social support and exchange networks. Money and time, according to this analysis, are key resources to participate in two distinct exchange circuits: monetary favour exchange and that involving care giving.
\end{abstract}

Palabras clave: precariedad laboral, redes sociales, aislamiento social, cohesión social.

Keywords: employment and labour precarity, social support networks, social isolation, social cohesion.

* Doctora en Sociología por la Universidad de Manchester e investigadora del CiESAS.

** Licenciada en actuaría por la UNAM, adscrita al CONEval en el área de medición de pobreza.

*** Maestra en Antropología por la University College London, estudiante del doctorado en Antropología Cultural en la Universidad de Chicago. 
To refuse to give, to fail to invite, just as to refuse to accept, is tantamount to declaring war; it is to reject the bond of alliance and commonality Marcel Mauss, The Gift

\section{Introducción ${ }^{1}$}

L

os trabajadores manuales que cuentan con empleo permanente y estable son cada vez más escasos en el México contemporáneo. La estabilidad del empleo (y del ingreso) les brinda una base de seguridad. Pero la gran mayoría de los trabajadores en México circulan en el mundo de la precariedad laboral. La falta de ingresos estables mantiene a muchos de ellos en situaciones de vulnerabilidad, enfrentando riesgos asociados a carencias que pueden llevar a catástrofes de las que difícilmente se recuperan. La precariedad laboral (bajos salarios, inseguridad en el empleo, ausencia de contrato y prestaciones sociales) no es un fenómeno que sólo exista en el sector informal de la economía. La precariedad avanza hacia empleos que hasta hace poco se consideraban protegidos en la industria, el comercio y los servicios (García, 2009; Standing, 2010).

La precariedad laboral está asociada a ingresos bajos y, por lo tanto, es generadora de pobreza (cuadro 1). A ello se suma la inexistencia de seguridad social, y dicha combinación conduce a situaciones de vulnerabilidad. Una enfermedad puede significar una catástrofe económica dados los gastos en servicios privados de salud. Las personas tienen que deshacerse de sus pertenencias, vender sus activos productivos, empeñar objetos y/o contraer deudas de difícil cancelación. Los salarios de los mercados de trabajo mexicanos hacen que el concepto trabajador pobre ("the working poor") siga siendo útil para describir a estas mayorías que no pueden darse el lujo del desempleo, pero que no encuentran cabida en los sectores más protegidos de la estructura ocupacional. ${ }^{2}$

1 Una primera versión de este documento fue elaborada en el marco del proyecto "Moving Jobs to the Center Stage in Mexico. Case study for the World Development Report 2013”.

2 Según Hale (1997), los trabajadores pobres o the working poor son aquellas personas que dedicaron 27 semanas del año o más a trabajar o buscar empleo y cuyos ingresos ajustados al tamańo del hogar son inferiores a la línea de pobreza. Estos trabajadores comparten ciertas características demográficas y económicas: 1) enfrentan problemas en el mercado laboral como desempleo, empleo de tiempo parcial involuntario y bajos ingresos; 2) viven con frecuencia en estructuras familiares que son más proclives a la pobreza: hogares con tasas altas de dependencia (básicamente presencia de niños). En los Estados Unidos, esta categoría de trabajadores está sobrerrepresentada entre las mujeres, los negros, los hispanos y los escasamente escolarizados. 
Cuadro 1. Ingreso laboral promedio por hora según distintas condiciones de trabajo, 2012

\begin{tabular}{cccccc}
\hline $\begin{array}{c}\text { Sin servicios } \\
\text { médicos }\end{array}$ & $\begin{array}{c}\text { Con servicios } \\
\text { médicos }\end{array}$ & $\begin{array}{c}\text { Sin otras } \\
\text { prestaciones }\end{array}$ & $\begin{array}{c}\text { Con otras } \\
\text { prestaciones }\end{array}$ & $\begin{array}{c}\text { Sin contrato } \\
\text { escrito }\end{array}$ & $\begin{array}{c}\text { Con contrato } \\
\text { escrito }\end{array}$ \\
\hline 26.3 & 36.8 & 21.2 & 34.8 & 21.5 & 37.6 \\
\hline
\end{tabular}

Fuente: Elaboración propia con base en la ENOE, primer trimestre de 2012.

Cuadro 2. Condiciones de trabajo de hombres y mujeres a nivel nacional, 2006 (porcentaje)

\begin{tabular}{cccccc}
\hline Sexo & $\begin{array}{c}\text { Micronegocios } \\
\text { precarios }\end{array}$ & $\begin{array}{c}\text { Jornada parcial } \\
\text { involuntaria }\end{array}$ & $\begin{array}{c}\text { Sin ningún tipo } \\
\text { de prestación }\end{array}$ & $\begin{array}{c}\text { Sin contrato } \\
\text { permanente }\end{array}$ & $\begin{array}{c}\text { No } \\
\text { sindicalizados }\end{array}$ \\
\hline Hombres & 31.1 & 19.1 & 60.8 & 73.6 & 90.6 \\
Mujeres & 41.0 & 36.3 & 56.9 & 71.0 & 87.2 \\
\hline
\end{tabular}

Fuente: Cifras tomadas de los cuadros 4 y 5 del análisis de García (2009) cuya base es la Encuesta Nacional de Ocupación y Empleo, segundo trimestre 2006.

En este artículo se argumenta que la calidad del empleo está ligada a la capacidad variable de hacer uso de los recursos de los trabajadores y sus familias, entre los que se encuentran su fuerza de trabajo y los bienes y servicios que fluyen a través de los vínculos y las redes sociales. Planteamos que el empleo permanente y estable está asociado a la existencia de redes sociales robustas en las que circula apoyo efectivo en momentos y situaciones de necesidad. La precariedad laboral, en cambio, con sus niveles altos de pobreza y carencias en múltiples dimensiones se asocia a una limitada participación en intercambios de apoyo. En estas situaciones no resulta fácil cumplir con las normas y principios de la devolución del favor. Es decir, las dimensiones no laborales de la vida de los trabajadores y sus familias se ven afectadas por la estabilidad o inestabilidad del empleo y de los ingresos. El intercambio social requiere recursos estables en la medida en que la reciprocidad implica el flujo de recursos (dinero y tiempo) que en contextos de pobreza y precariedad laboral son limitados (González de la Rocha, 2000; 2015 [2001]). Bazán (1999) y Estrada (1996) mostraron que los hogares de los trabajadores se atomizan y la ayuda mutua desaparece cuando sus fuentes de empleo/ingresos dejan de existir. Se ha documentado, asimismo, que los recursos monetarios y el tiempo son elementos cruciales para la participación y existencia misma del trabajo por cuenta propia y para la instrumentación de estrategias colectivas de trabajo (Pahl, 1984; González de la Rocha, 1999; 2015 [2001]). ${ }^{3}$ La precariedad laboral y la irregularidad de

3 En los conjuntos habitacionales de la Inglaterra thatcheriana, donde habitaba un alto porcentaje de desempleados, no existían los suficientes flujos monetarios para contratar servicios informales realizados por vecinos y parientes (limpieza de vidrios, arreglos de plomería, etc.), porque todos estaban igualmente pobres. Los desempleados fueron perdiendo contacto social esencial para la obtención de información 
los ingresos dan lugar a procesos de acumulación de desventajas que incluyen dificultades para emprender negocios familiares y el deterioro de los vínculos sociales (González de la Rocha \& Villagómez, 2006).

Este análisis pone a prueba los hallazgos etnográficos expuestos arriba mediante el escrutinio estadístico de la relación entre el empleo y el acceso a intercambios de ayuda. Nos interesa saber si el dinero y el tiempo son los recursos más importantes para la participación en redes sociales de apoyo; si la relación entre el empleo y el intercambio social existe, y en su caso, si las cualidades del empleo determinan cualidades de los vínculos sociales, en ambos sentidos. Nuestra hipótesis es que la relación existe, que el empleo seguro y protegido afianza el acceso a redes sociales de apoyo y que la precariedad produce procesos de deterioro de los vínculos sociales. Por último, planteamos que el tiempo y el dinero son recursos clave para que los individuos puedan participar en redes sociales de apoyo. Si las hipótesis encuentran respaldo en el análisis estaremos contribuyendo al conocimiento de fenómenos más amplios y de enorme importancia para la comprensión del México actual. Tal es el caso, por ejemplo, de la llamada cohesión social (o su inexistencia, véase Tokman, 2007), relacionada con la confianza/desconfianza entre las personas y la que éstas tienen en las instituciones y en la sociedad en su conjunto, desde el intercambio social entre vecinos y familiares hasta la participación en asociaciones y acciones colectivas. La participación en la vida social está moldeada por la confianza que tenemos en las autoridades, las instituciones, la familia y los vecinos. Si la exclusión social y la precariedad producen atomización, incredulidad, escepticismo y restricciones para ayudar al otro, podemos argumentar que la falta de oportunidades laborales en empleos seguros, capaces de brindar protección al trabajador, forma parte de la desconfianza y la inseguridad que caracterizan hoy al país y sufren los ciudadanos atrincherados en sus hogares y en sus respectivas comunidades.

\section{Aclaraciones conceptuales}

\section{Trabajo, empleo y ocupaciones}

Este análisis se enmarca en una perspectiva que ve el trabajo como un recurso central en la vida de las personas en tanto que interconecta los modos de

sobre posibles empleos, no podían comprar herramientas y equipo de trabajo (Pahl, 1984). La pérdida del empleo dificulta la inversión de recursos en la producción a pequeña escala; no hay recursos para echar a andar pequeños negocios. 
subsistencia de los trabajadores y sus familias con la sociabilidad y la cohesión social. ${ }^{4}$ Un "buen trabajo/empleo", según Bourguignon (2005), ofrece un ingreso decente y brinda protección social adecuada.

El concepto trabajo refiere al conjunto de actividades humanas productivas y creativas que se realizan con la finalidad de obtener/producir bienes, servicios o algún tipo de compensación material o social. El trabajo es clave para entender la supervivencia y reproducción material y cultural. Mediante el trabajo se producen transformaciones en la cultura material; las formas en las que se trabaja pueden ser vistas como marcadores culturales que distinguen a unos grupos de otros. La etnografía ha documentado como trabajo desde las actividades más monótonas, duras, sucias y humillantes hasta el trabajo más artístico (Kingsolver, 2007 [1996]). Se han estudiado las estructuras laborales y la organización del trabajo; las percepciones y los significados del trabajo. La reproducción de las identidades de clase fue un tema muy socorrido de los estudios del trabajo (Kingsolver, 2007 [1996]). La investigación sobre distintos contextos industriales y del trabajo dio importantes frutos en México, donde los estudios sobre la industria textil, la automotriz, la minería y otras ramas industriales iluminaron los procesos de conformación de la clase obrera mexicana (Arias \& Bazán, 1980; Novelo, 1980; Nieto, 1984; Sariego, 1990). Importantes investigaciones se centraron en explicar los vínculos entre la producción a gran escala — en empresas formales - y la maquila a domicilio que absorbe grandes cantidades de mano de obra barata, mayoritariamente femenina y sin prestación alguna (Fernández Kelly, 1983; Benería \& Roldán, 1987; Arias, 1988). La organización social de los mercados laborales, las estructuras y dinámicas de los hogares de los trabajadores y las respuestas sociales y familiares a las crisis económicas atraparon la atención de estudiosos de la realidad mexicana para comprender procesos de urbanización e industrialización, organización de la clase trabajadora, desempleo, precarización del trabajo y las

4 Hay diversas definiciones del concepto cohesión social y no hay consenso sobre cómo medirla. Tres factores son recurrentes en la discusión: a) los valores compartidos, b) la confianza y c) la participación cívica. El que mayor potencial de análisis tiene es el de la participación cívica/social, porque está relacionado con los dos primeros y porque hay más posibilidades para pasar de la abstracción del concepto a su observación empírica. Mediante la participación cívica pacífica y el diálogo, los individuos construyen consensos. La participación es un indicador del grado de confianza en las instituciones. El tipo de empleo parece definir en buena medida la forma y el grado en el que los individuos participan en la construcción de consensos, en la vida y los problemas de la sociedad. Se ha planteado que los trabajadores asalariados están más involucrados cívicamente que, por ejemplo, los autoempleados, los desempleados y los excluidos de la fuerza laboral quienes, a diferencia de los primeros, muestran los niveles más bajos de compromiso e involucramiento cívico (Banco Mundial, 2012). El trabajo, entonces, imprime su sello en el grado de confianza en las instituciones y la voluntad o disposición para participar en la vida de la sociedad. 
implicaciones de estos fenómenos en la vida social y familiar de los trabajadores (García, Muñoz \& Oliveira, 1982; Escobar, 1986; González de la Rocha, 1986; 1994; Bazán, 1999). El trabajo reproductivo no remunerado, desde tareas de crianza y socialización de los niños y cuidado de dependientes hasta la limpieza, compra de insumos domésticos y producción de bienes para el consumo familiar, ha sido también conceptualizado como trabajo y como una de las fuentes de ingreso de los hogares (ingreso entendido en sentido amplio, Wallerstein, Martin \& Dickinson, 1982), sin las cuales no es posible explicar la sobrevivencia y reproducción social de los trabajadores (García, Muñoz \& Oliveira, 1982; González de la Rocha, 1986; 1994). Estos análisis han contribuido a satisfacer la necesidad de entender al trabajo en todas sus formas y a los grupos domésticos como unidades organizadas para realizar distintos tipos de trabajo (Pahl, 1984).

Las distintas formas que asume el trabajo, y el hecho de que los tipos de trabajo y los significados del mismo son productos históricos, moldeados por el contexto, hace de su comprensión una tarea compleja. Aquí se distinguen los conceptos de trabajo, empleo y ocupación de una manera simple y operativa y centramos el análisis en el empleo. Con el concepto trabajo aludimos a las actividades, remuneradas o no, que como miembros de una sociedad realizamos para obtener bienes o servicios (para el consumo o para la venta), para lograr la sobrevivencia y reproducción. Mediante el trabajo se obtienen compensaciones (el trabajo retribuye), pero no siempre remuneraciones. Un empleo subordinado (INEGI, 2005) es una relación laboral que se da con una instancia superior a la cual se le rinde cuentas (un jefe, un consejo o un patrón). El empleado ocupa una plaza o un puesto de trabajo. Las personas que lo desempeñan pueden o no recibir una remuneración y, por ello, se clasifican en trabajadores remunerados y no remunerados. La ocupación, por último, es entendida “[...] en un plano más amplio, donde no sólo se incluye a quienes trabajan para alguien sino también a quienes cuentan con un negocio propio o realizan una actividad por su cuenta. Ocupación es, pues, un término más amplio, en tanto que el de empleo es más específico y caracterizado por una relación de subordinación" (INEGI, 2005: p. 16). Bourguignon (2005), a pesar de que no ofrece la profundidad conceptual que sería necesaria, nos brinda claridad operativa respecto de los buenos y los malos empleos. Los buenos empleos son los que dan a los trabajadores un pago decente y protección social adecuada. Los malos son, por el contrario, los que se desempeñan bajo condiciones difíciles, con bajos salarios y sin protección social. La ausencia de un seguro de desempleo ha significado que en los llamados paises en desarrollo "[...] el desempleo abierto está de hecho limitado a un pequeño número de personas que tienen suficientes recursos para esperar a que un empleo, con las características que buscan, surja [...]" (Bourguignon, 
2005: p. 3). ${ }^{5}$ Por ello, según este autor, los desempleados utilizan sus propios recursos o reciben el apoyo de sus familias mientras esperan "buenos empleos". La mayoría de los trabajadores, sin embargo, se ven forzados a abandonar esta categoría para buscar y aceptar ocupaciones que, aunque precarias, les permitan sobrevivir. Las jornadas extremadamente largas o involuntariamente parciales, en pésimas condiciones y con muy bajos ingresos son el común denominador de los mercados laborales. Estas personas no son desempleadas, "[...] tienen un empleo, pero simplemente tienen un mal empleo" (Bourguignon, 2005: p. 3). De acuerdo con estos planteamientos, la mayor parte de los hombres y mujeres ocupados en México tienen malos empleos (cuadro 2).

\section{Fuentes de ingresos de los grupos domésticos}

Los bajos salarios fuerzan la solidaridad y la instrumentación de estrategias de trabajo que incluyen a los miembros del hogar, incluso desde etapas muy tempranas de sus vidas. Se trata de estrategias colectivas en las que se combinan muy diversos tipos de trabajo (asalariado, por cuenta propia, no remunerado, de producción de bienes y servicios para el consumo familiar). La diversidad de fuentes de ingreso y la heterogeneidad ocupacional de los hogares constituyen los mecanismos de subsistencia de los trabajadores pobres. González de la Rocha formuló un modelo para explicar la manera en la que los trabajadores en Guadalajara organizaban sus vidas en los años previos a la crisis económica de los ochenta. Los recursos de la pobreza conforman un sistema de trabajo colectivo de sobrevivencia y reproducción social basado en cuatro pilares al interior de los hogares: 1) trabajo asalariado de varios miembros del hogar; 2) trabajo destinado a la pequeña producción de bienes y servicios para la venta; 3) trabajo invertido en la producción de bienes y servicios para el consumo familiar,

5 Bourguignon plantea que la dicotomía empleo-desempleo es "[...] de relevancia obvia en el mundo desarrollado" y asume su utilidad heurística para la comprensión del trabajo en esos contextos. En contraste, Pahl (1984) argumenta que el empleo en Inglaterra ha sido históricamente irregular. Durante 1860-1920, los trabajadores realizaban distintos tipos de trabajo de manera simultánea, muchos de ellos subempleos (Samuel, 1975, citado por Pahl, 1984). El mundo desarrollado contemporáneo no se escapa de la precarización laboral que pone en tela de juicio la utilidad de dicha dicotomía. Pahl plantea que el hallazgo de Samuel no es una rareza del pasado y que el trabajo precario y eventual, muchas veces sin pago, ha existido siempre en la Gran Bretańa. Según estimaciones de la Unión Europea, la economía informal fue responsable de entre el 7 y el 16\% del PIB del área económica europea en los ańos noventa, lo que equivale a alrededor de 75 billones de libras esterlinas de la economía británica. Los empleos informales (no registrados, sin contrato ni prestaciones) han aumentado a lo largo y ancho de las economías de Europa Central y del Este y el empleo informal aumenta como respuesta a crisis económicas y a la pobreza, out of need, not greed (Katungi, Neale \& Barbour, 2006).

M. González de la Rocha, M. Moreno Pérez, I. Escobar | Empleo e intercambio social en México Perfiles Latinoamericanos, 24(47) | FLACso México | pp. 225-258 | DoI: 10.18504/pl2447-012-2016 
y 4) trabajo de mantenimiento de redes sociales de apoyo. En la década de los ochenta, en Guadalajara, la participación de mujeres en todos estos tipos de trabajo fue crucial para la organización y economía del hogar. Para algunos hogares, la sobrevivencia era difícil, pero los empleos - formales e informales - existían. Algunos trabajadores optaban por salir del empleo para realizar ocupaciones por su cuenta y retornaban después al mercado laboral. El empleo informal era relativamente atractivo. Según Escobar (1986), el empleo informal podía ofrecer remuneraciones tan altas o más que el formal porque en los pequeños talleres rige el destajo como forma de pago. Los hogares combinaban distintos empleos y formas de trabajo. Del empleo formal se obtenía, además de salarios, acceso a seguridad social. Del empleo informal se obtenían ingresos monetarios y una conveniente flexibilidad de horarios que permitía cierta compatibilidad entre los ámbitos productivo y reproductivo, especialmente importante para las mujeres. La regularidad de los ingresos nutría otras actividades laborales del hogar (producción de bienes y servicios para la venta o para el consumo familiar). Se formaba parte de redes sociales y de cadenas de intercambio social. Los aislados sociales eran tan escasos que fueron estudiados como anomalía o casos desviantes (González de la Rocha, 1986, 1994).

Los hogares durante la crisis de los años ochenta fueron el mejor ejemplo de que el recurso más importante de los pobres es el trabajo (Moser, 1996). Se instrumentaron estrategias basadas en la intensificación del uso de la fuerza de trabajo del hogar con una dosis importante de intercambio social, a través del uso intensivo de redes de relaciones sociales. Estas medidas amortiguaron el impacto de la crisis (González de la Rocha, 1994). Aunque empezaban a escasear los empleos formales, los trabajadores se emplearon más a sí mismos y a sus parientes y amigos (en pequeñísimos negocios informales); las mujeres casadas, con hijos y cargas domésticas, multiplicaron su presencia en los mercados laborales (González de la Rocha \& Escobar, 1986; García \& Oliveira, 1992). Lo anterior no fue suficiente para proteger el consumo y las personas debieron apretarse el cinturón (González de la Rocha, 1991).

El modelo sufrió una fructífera revisión cuando las sucesivas crisis económicas (a la crisis de los ańos ochenta le siguieron otras durante la década siguiente) mermaron las capacidades familiares de mantener intactos estos cuatro distintos tipos de trabajo/fuentes de ingresos. La erosión laboral del inicio de los años noventa socavó la organización social de los grupos domésticos. La falta de empleos formales y la saturación de los informales hicieron más difícil la vida de los trabajadores porque redujeron sus capacidades de responder con el manejo tradicional de los recursos de la pobreza: manipulando e intensificando el uso de su fuerza de trabajo. El modelo de los recursos de la pobreza dejó de gozar de viabilidad empírica y perdió capacidad explicativa. En su lugar, surgió otra forma de describir 
la realidad: la pobreza de recursos resultado de la creciente precarización laboral y la intensificación de la pobreza (González de la Rocha, 2015 [2001]). Sin los ingresos provenientes de un empleo seguro es difícil que los grupos domésticos cuenten con los recursos necesarios para abonar las actividades laborales 2, 3 y 4 de los cuatro pilares que anteriormente nutrieron, junto con el ingreso remunerado en forma de salarios, a las economías familiares. Sin ingresos estables las personas no tienen recursos para formar parte de redes sociales en donde la reciprocidad es la norma fundamental del intercambio. Pero tampoco tienen los recursos para invertir en negocios familiares de producción de bienes para la venta, e incluso ven mermadas sus posibilidades de llevar a cabo la producción de bienes para el consumo familiar (González de la Rocha, 2015 [2001]). Es importante averiguar, en el marco de estos procesos, si los vínculos sociales han seguido debilitándose como consecuencia de los malos empleos que actualmente predominan en los mercados laborales mexicanos.

\section{Intercambio social}

La sociedad, según Mauss (2011[1950]), debe entenderse como un sistema cíclico de dones (cycling gift system). El mayor intercambio de bienes alrededor del mundo y a lo largo de la historia, según este autor, ha sido constituido por ciclos de devoluciones obligatorias de bienes y servicios — los dones—. Cada don es parte de un sistema de reciprocidad en el que se enlazan el honor del que da y el del que recibe. Los dones recibidos deben regresarse de alguna forma específica — dictada por las relaciones sociales en juego—, lo que da lugar a un ciclo perpetuo de intercambios. Si quien recibe fracasa y no logra devolver el don, no sólo pierde honor al romper el ciclo sino que también deja de alimentar las relaciones sociales que constituyen el sistema y se mantienen de él. Mientras que las transacciones de mercado pueden ocurrir entre personas que no tienen una relación social directa, el intercambio de dones depende de una relación preexistente. La transacción de mercado no crea una relación social directa. En contraste, el intercambio de dones alimenta y crea relaciones sociales ricas y robustas. Las transacciones de mercado, al operar a partir de una moneda estándar, pueden ser inmediatamente pagadas. Los bienes intercambiados son cuantificados y la transacción se finiquita en el momento. Por lo tanto, la relación del vendedor y del comprador dura unos momentos, sólo durante la transacción misma. ${ }^{6}$ En

6 Con excepción del crédito que extiende el periodo en el que se realiza la transacción. Es interesante que el crédito es también un sistema basado en la confianza, aunque sería necesario investigar con detenimiento sus características y lo que lo distingue (o asemeja) al intercambio social aquí descrito. 
contraste, el intercambio de dones se lleva a cabo en plazos más largos y las relaciones sociales en juego deben ser alimentadas y mantenidas durante el tiempo que toma devolver el don inicial. Así, el que recibe se vuelve deudor y el que da se convierte en acreedor en cadenas que - si estos intercambios continúan- no tienen fin. La relación social establecida no tiene fecha de expiración (Roberts, 2011 [1973]). La importancia de la teoría del don yace en dos puntos: 1) las relaciones sociales son creadas y se mantienen a partir de intercambios diferidos de bienes no fácilmente cuantificables, y 2) estos intercambios son el cemento o social glue del que nos habla Pahl (1991). Esto quiere decir que sin intercambio social no hay sociedad $\longrightarrow$ o cohesión social. ${ }^{7}$

Las implicaciones de estos dos puntos son centrales para nuestro análisis. $\mathrm{Si}$ aceptamos a) que los sistemas de intercambio social (gift-exchange) y de intercambio de mercado (market-exchange) son dos tipos ideales weberianos y que, en realidad, cada sociedad incorpora elementos de ambos y cada individuo participa en ambos tipos de intercambio, y b) que en toda sociedad los intercambios diferidos de bienes no cuantificados implican la puesta en circulación de dichos bienes o recursos (entre los que se encuentran tiempo, apoyos afectivos en forma de servicios y favores y recursos monetarios), podemos concluir que c) las relaciones sociales tienen costos y por tanto dependen de flujos estables de ingresos (González de la Rocha, 1999; 2000; 2015 [2001]); y d) la cohesión social, dado que depende del intercambio diferido de bienes no cuantificados, depende también de la disponibilidad de recursos monetarios estables. Tomando en cuenta este punto, se puede argumentar que la cohesión social, o el llamado social glue, tiene una distribución social desigual y paralela a la distribución de recursos. El aislamiento social (ausencia de intercambio) puede ser visto como resultado de 1) la falta de recursos para mantener reciprocidades y por lo tanto relaciones sociales, y 2) la pérdida de interés en respetar o acogerse a las convenciones morales - o normas y principios que dictan la manera en la que se espera que los individuos actúen para seguir formando parte de las relaciones de intercambio social: las obligaciones- como resultado de la no pertenencia a redes sociales (Pahl, 1991; Pahl \& Wallace, 1985).

En el siguiente apartado presentamos los resultados del análisis. Es necesario aclarar que el nuestro no es el primer acercamiento al fenómeno en cuestión. González de la Rocha \& Villagómez (2008) mostraron que la precariedad

7 Aquí hacemos uso del concepto descriptivo más que normativo de "cohesión social," misma que entendemos como solidaridad de grupo (Norton \& De Haan, 2013). Esta definición, interpretada por Norton y De Haan como cohesión social "cruda", difiere de la concepción normativa de la cohesión social pues no postula a la equidad, a la inclusión y a la tolerancia como condiciones necesarias para una sociedad profundamente cohesiva. Aunque también creemos que estos valores y características son deseables e importantes, su discusión va más allá del propósito de este texto. 
laboral conduce a situaciones de aislamiento social, pero que otros factores, como la vejez y la migración de retorno forzada (la migración de retorno como producto de las deportaciones), también socavan la capacidad para entablar y mantener vínculos sociales y relaciones de ayuda mutua. Rabell et al., mediante el análisis de la ENDIFAM, concluyen que los factores que mayor efecto tienen en el aislamiento social —asociados al hecho de no recibir ayuda en situaciones de crisis - son: $a$ ) condición socioeconómica precaria, b) edad avanzada y c) falta de personas cercanas afectivamente (Rabell, 2009). Poco más de la mitad de los entrevistados por la ENDIFAM declaró no dar ni recibir ayudas en la vida cotidiana. Las situaciones de crisis, sin embargo, apelan a la solidaridad familiar y social: la proporción de personas que declaran dar y recibir ayuda es el doble, en tiempos de crisis, que la reportada en la vida cotidiana. Estos resultados refuerzan los hallazgos de las investigaciones etnográficas anteriormente citadas - y el argumento de este documento- cuando encuentran que la ayuda mutua se incrementa con el ingreso (Rabell \& D’Aubeterre, 2009). El hecho de que las personas que pertenecen a los estratos sociales más altos tienen mayor capital social es perfectamente consistente con nuestro argumento. No por nada Bourdieu (1984) acuñó este concepto en su estudio de las élites francesas, La Distinción.

\section{Empleo y acceso a redes sociales de apoyo: resultados del análisis}

En un análisis anterior (González de la Rocha, Moreno \& Escobar, 2012), exploramos la relación entre el tipo de empleo y el acceso a redes sociales de apoyo. ${ }^{8}$ Dicho análisis sugirió que carecer de prestaciones laborales es lo común y que el empleo ha sufrido transformaciones importantes a partir de 2006: el desempleo ha aumentado particularmente entre los jóvenes (12 a 19 ańos); los ingresos laborales se han deteriorado; el porcentaje de trabajadores sin contrato escrito se ha mantenido en niveles altos (casi el 50\% de los trabajadores subordinados y remunerados carece de contrato). Encontramos también una clara asociación entre pobreza y fragilidad de redes sociales; entre tipo de empleo y pobreza y entre tipo de empleo y acceso diferencial a los favores y apoyos que brindan los vínculos sociales. Observamos que los favores que tienen que ver con el recurso dinero y los que tienen relación con el

8 Tanto el análisis descriptivo anterior como el de clases latentes que se presenta a continuación, utilizó los datos del MCS-ENIGH. Agradecemos la generosidad e inagotable paciencia de Fernando Cortés, quien nos sugirió darle más fuerza al análisis y nos acompañó en este proceso (de lo descriptivo a las clases latentes).

M. González de la Rocha, M. Moreno Pérez, I. Escobar | Empleo e intercambio social en México Perfiles Latinoamericanos, 24(47) | FLACso México | pp. 225-258 | DoI: 10.18504/pl2447-012-2016 
recurso tiempo tienen lógicas diferentes y su acceso a los mismos es también distinto. Los favores más accesibles parecen ser los que se relacionan con la variable tiempo mientras que los favores vinculados con dinero son aparentemente menos accesibles. Es decir, es más común dar y recibir favores cuando la "moneda" que circula en el intercambio social es el tiempo (cuidados, compañía) y menos común cuando la moneda es el dinero (préstamos monetarios y contribuciones en efectivo).

\section{Metodología de clasificación de los hogares: grado de confianza} en el acceso a los favores

El propósito del presente análisis es brindar información suficiente para sustentar que a partir de las seis preguntas sobre acceso a ayuda de distintas modalidades incorporadas en los Módulos de Condiciones Socioeconómicas de la Encuesta Nacional de Ingresos y Gastos de los Hogares (MCS-ENIGH del INEGI), es posible encontrar la movilización de dos tipos de recursos (o "moneda"): dinero y tiempo. Estos son movilizados para dar y recibir distintos tipos de ayuda entre los miembros de redes sociales, no de manera caprichosa sino en función de ciertos patrones. Queremos probar que la percepción de recibir favores/ayuda (a la cual de ahora en adelante nos referiremos como el grado de confianza) guarda una estrecha relación con variables asociadas al ingreso, tipo de empleo, carencias sociales y otras variables sociodemográficas.

El análisis se realizó para los años 2008, 2010 y 2012 y se divide en tres etapas. La primera consiste en un Análisis Factorial Confirmatorio (AFC) para corroborar que la hipótesis sobre la circulación de dos monedas o recursos clave para el intercambio de dos tipos de ayuda es correcta. El AFC permite someter a prueba que las observaciones provienen de variables latentes que se pueden identificar a través de las covarianzas entre las variables observadas. ${ }^{9} \mathrm{El}$ AFC se centra únicamente en el modelo de medición. Una vez hecho el análisis contaremos con los puntajes para cada factor. Dichos puntajes servirán de insumo para la construcción de las diferentes clases de hogares (en tanto sus capacidades para acceder al intercambio de favores). Una vez cumplido el análisis exploratorio sobre el número de factores a los que se puede reducir la dimensionalidad de un conjunto de variables, se desarrolla el siguiente sistema de ecuaciones en términos de dichos factores para cada observación.

9 Las variables manifiestas son unidireccionales y reflectivas, lo que significa que éstas guardan una estructura de correlación con el constructo identificado (Brown, 2006). Las no recursivas son bidireccionales. Esto quiere decir que en estas últimas no se puede establecer unidireccionalidad en la relación. 


$$
\begin{gathered}
x_{i, 1}=\alpha_{1}+\lambda_{1,1} F_{i, 1}+\lambda_{1,2} F_{i, 2}+\cdots+\lambda_{1, m} F_{i, m}+\varepsilon_{i, 1} \\
\ldots \\
x_{i, 1}=\alpha_{j}+\lambda_{j, 1} F_{i, 1}+\lambda_{j, 2} F_{i, 2}+\cdots+\lambda_{j, m} F_{i, m}+\varepsilon_{i, j} \\
\cdots \\
\cdots \\
x_{i, p}=\alpha_{p}+\lambda_{p, 1} F_{i, 1}+\lambda_{p, 2} F_{i, 2}+\cdots+\lambda_{p, m} F_{i, m}+\varepsilon_{i, p}
\end{gathered}
$$

Donde $m<p$,

$x_{i, j}=$ variable $j$ de la $i$ - ésima observación

$\alpha_{i}=$ intersecciones

$\lambda_{j, k}=$ cargas de los factores

$F_{i, k}=$ factores

$\varepsilon_{i, j}=$ residuales

La segunda etapa del análisis es la elaboración de las clases de hogares de acuerdo a los puntajes factoriales. El Análisis de Clases Latentes (ACL) permite la formación de tipologías de hogares que son homogéneas dentro de grupos, pero heterogéneas entre grupos. La ordenación es paramétrica y tiene la ventaja de que la determinación del número de grupos no es arbitraria, sino que se sujeta a criterios estadísticos (Nylund, Asparouhov \& Muthen, 2007; Hagenaars \& McCutheon, 2002). Las clases o estratos representan los conjuntos de hogares distintos entre sí, según los distintos grados de confianza que las personas en el hogar tienen de recibir ayuda asociada a las variables dinero y tiempo. Dichos estratos se elaboraron mediante el método de ACL, puesto que, a diferencia de otros métodos de estratificación, éste nos provee de indicadores que permiten determinar el número de estratos. Los modelos de clases latentes suponen que en un conjunto de variables observadas se encuentran varios subgrupos de observaciones que corresponden a diferentes funciones de distribución. El ACL sirve para identificar estas funciones de distribución y evaluar la probabilidad de pertenencia de cada observación a cada clase latente. Es importante recalcar que al utilizar el ACL para diferentes 
muestras, no necesariamente se contará con el mismo número de clases en todos los casos, sin embargo, en el caso de este análisis se encontró, con base en las medidas de ajuste, que el número óptimo de clases para los tres años fue el mismo.

La tercera etapa fue un análisis a profundidad sobre la situación social y económica de los hogares, el poder adquisitivo y las características de las personas que pertenecen a la fuerza laboral, diferenciando según su grado de confianza en el acceso a las redes sociales.

\section{El modelo propuesto}

Nos propusimos probar la hipótesis de que existen dos tipos de ayuda, cada uno con su "moneda" específica, en la circulación de bienes y servicios: uno relacionado con el dinero y otro en la que el recurso que lo hace posible es el tiempo. Se trata de percepciones porque la encuesta pregunta sobre el grado de dificultad que las personas creen tener para acceder a ayuda en caso de necesidad (grado de confianza). Las preguntas son:

1. ¿Cree usted que si necesitara pedirle a alguien la cantidad de dinero que se gana en su hogar en un mes, le sería? (grado de dificultad: imposible, difícil, fácil, muy fácil, ni fácil ni difícil).

2. ¿Cree usted que si necesitara pedir ayuda para que lo(a) cuiden a usted en una enfermedad, le sería?

3. ¿Cree usted que si necesitara pedir ayuda para conseguir un trabajo, le sería?

4. ¿Cree usted que si necesitara pedir ayuda para que lo(a) acompañen al doctor, le sería?

5. ¿Cree usted que si necesitara pedir cooperación para realizar mejoras en su colonia o localidad, le sería?

6. ¿Cree usted que si necesitara pedir ayuda para que cuiden a los(as) niños(as) en este hogar, le sería?

Análisis factorial confirmatorio para redes asociadas al tiempo y al dinero

El modelo que se prueba por medio del AFC es el siguiente: 


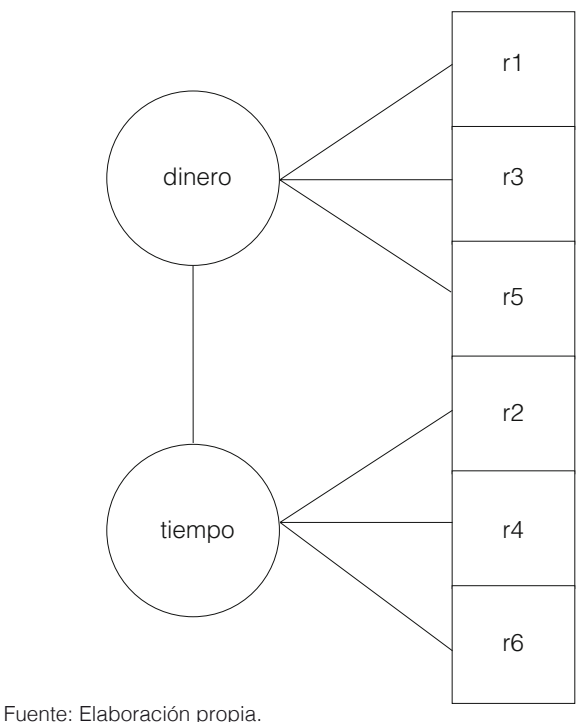

¿Cree usted que si necesita pedirle a alguien la cantidad de dinero que se gana en su hogar en un mes le sería?

¿Cree usted que si necesitara pedir ayuda para conseguir un trabajo, le sería?

¿Cree usted que si necesitara pedir cooperación para realizar mejoras en su colonia o localidad, le sería?

¿Cree usted que si necesitara pedir ayuda para que lo(a) cuiden a usted en una enfermedad, le sería?

¿Cree usted que si necesitara pedir ayuda para que lo(a) acompañen al doctor, le sería?

¿Cree usted que si necesitara pedir ayuda para que cuiden a los(as) niños(as) en este hogar, le sería?

El modelo factorial confirmatorio contiene dos variables latentes: dinero, que se mide a través de las variables manifiestas $\mathrm{r} 1, \mathrm{r} 3$ y r 5 , y tiempo, que se mide a través de r2, r4 y r6. El AFC mide con cierto grado de error dichas dimensiones (indicadas con $e i$ ). Asociados al dinero están los préstamos monetarios, las contribuciones en efectivo para realizar mejoras en el entorno y la ayuda para conseguir un trabajo. Con la variable latente tiempo están relacionadas las preguntas que indagan sobre el acceso a ayuda para el cuidado en una enfermedad, compañía para ir al doctor y para cuidado de los menores en el hogar.

Para determinar si el modelo presentado es plausible, se consideraron las siguientes medidas, en donde el CFI (por sus siglas en inglés, Comparative Fit Index), propuesto por Hu \& Bentler (1999) y Bentler (1990), permite ajustar el modelo especificado al compararlo con un modelo nulo. El rango de posibles valores del CFI varía entre 0 y 1 , por lo que los valores mayores o iguales a 0.90 indican un buen ajuste. En el caso del índice RMSEA (por sus siglas en inglés, Root Mean Square Error Approximation), los valores más pequeños de 0.05 indican un buen ajuste (Ridgon, 1996; Steiger \& Lind, 1980). Finalmente, el SRMr (por sus siglas en inglés, Standardized Root Mean Square Residual) indica un buen ajuste si sus valores son inferiores a 0.05 (Jöreskog \& Sörbom, 1981). 
Cuadro 3. Medidas de bondad ajuste del AFC, 2008-2012

\begin{tabular}{llll}
\hline Bondad de ajuste & 2008 & 2010 & 2012 \\
\hline CFI (Comparative Fit Index) & 0.985 & 0.989 & 0.989 \\
SRMR (Standardized Root Mean Square Residual) & 0.025 & 0.020 & 0.018 \\
RMSEA (Root Mean Square Error Of Approximation) & 0.040 & 0.033 & 0.032 \\
\hline
\end{tabular}

Fuente: Elaboración propia con base en los MCS de la ENIGH 2008, 2010 y 2012.

Tanto el RMSEA como el SRMR son menores a 0.05 y el CFI es bastante alto, de 0.985 o mayor. Con estos resultados contamos con suficiente evidencia para afirmar que nuestro modelo es plausible para los tres años, es decir, que no ha sido rechazado por la evidencia empírica.

\section{Análisis de clases latentes usando los factores de tiempo y dinero}

Una vez calculados los puntajes factoriales, nos interesa conocer qué tipo de hogares tienen los puntajes más altos y los puntajes más bajos para determinar el grado de confianza en el acceso a los recursos que circulan en las redes, para después analizar si los distintos grados de confianza están relacionados con el nivel de ingreso y el tipo de empleo/ocupación. Nos interesa averiguar, además, si el hecho de que los hogares sean o no pobres impacta el grado de confianza de sus miembros para determinar si se observa la relación esperada entre empleo precario, pobreza, ingreso y otras variables asociadas a carencias sociales con el acceso a redes sociales. Para ello, procedimos a clasificar los hogares en estratos o clases mediante el ACL. De este modo obtuvimos una serie de medidas que nos indicaron el número óptimo de estratos. En los cuadros 4,5 y 6 se muestran las medidas que fueron tomadas a consideración para escoger el número de clases. ${ }^{10}$

10 El criterio de información bayesiano, BIC por sus siglas en inglés, es un criterio de selección de un modelo de entre un conjunto finito de modelos. Entre menor sea el valor del BIC ajustado mejor es el ajuste. El Lo-Mendell-Rubin Likelihood Ratio Test compara la mejora en el ajuste de un modelo con k-1 clases y un modelo con k clases. Entre menor sea este valor en el test, se tiene un mejor ajuste (Nylund, Asparouhov \& Muthén, 2007). La entropía es una medida de qué tan claramente están distinguidas las clases y se basa en qué tan distintas son las probabilidades estimadas de pertenecer a cada clase de cada hogar, por esta razón, a mayor entropía el modelo distingue mejor entre clases. Una vez que se tienen las probabilidades estimadas de pertenecer a cada clase y se ha determinado a qué clase pertenece cada hogar, el rango de probabilidades no es más que el mínimo y el máximo de dichas probabilidades; se busca que estas probabilidades sean lo más altas posible para evitar que un hogar tenga probabilidades parecidas de pertenecer a dos clases distintas. Finalmente, el porcentaje en la clase indica cuáles son el mínimo y el máximo porcentaje de hogares que caen en cada clase. Se busca que cada clase tenga al menos 5\% de hogares. 
Cuadro 4. Medidas para la determinación del número óptimo de clases latentes, 2008

\begin{tabular}{ccccccc}
\hline \multicolumn{7}{c}{2008} \\
\hline \multirow{2}{*}{ Clases } & BIC ajustado & Valor & Valor de $P$ & Entropía & $\begin{array}{c}\text { Probabilidades de } \\
\text { clasificación correc- } \\
\text { ta (rango) }\end{array}$ & $\begin{array}{c}\text { Porcentaje en la } \\
\text { clase (rango) }\end{array}$ \\
\cline { 2 - 4 } 2 & -103538 & 35572 & 0.0001 & 0.813 & $.918-.960$ & $33.4-66.6$ \\
3 & -121917 & 17861 & 0.0001 & 0.814 & $.882-.930$ & $15.1-57.5$ \\
4 & -136011 & 15501 & 0.0001 & 0.850 & $.902-.958$ & $10.6-43.6$ \\
5 & -138647 & 9494 & 0.0001 & 0.803 & $.832-.960$ & $5.4-34.7$ \\
6 & -147369 & 5478 & 0.0001 & 0.882 & $.884-.974$ & $8.8-30.3$ \\
7 & -151642 & 4170 & 0.0001 & 0.885 & $.838-.986$ & $7.7-27.2$ \\
\hline
\end{tabular}

Fuente: Elaboración propia con base en el MCS de la ENIGH 2008.

Cuadro 5. Medidas para la determinación del número óptimo de clases latentes, 2010

\begin{tabular}{ccccccc}
\hline \multicolumn{7}{c}{ Lo-Mendell-Rubin LRT Test } \\
\cline { 3 - 4 } Clases & BIC ajustado & Valor & Valor de P & Entropía & $\begin{array}{c}\text { Probabilidades de } \\
\text { clasificación correcta } \\
\text { (rango) }\end{array}$ & $\begin{array}{c}\text { Porcentaje en la } \\
\text { clase (rango) }\end{array}$ \\
\hline 2 & -117549 & 33192 & 0.0001 & 0.795 & $.912-.956$ & $34.3-65.7$ \\
3 & -137059 & 18960 & 0.0001 & 0.814 & $.874-.921$ & $14.6-57.5$ \\
4 & -149829 & 12419 & 0.0001 & 0.843 & $.895-.955$ & $9.7-44.0$ \\
5 & -155438 & 5467 & 0.0001 & 0.840 & $.839-.953$ & $8.3-33.2$ \\
6 & -158699 & 3188 & 0.0001 & 0.830 & $.784-.948$ & $5.8-31.5$ \\
7 & -163005 & 2254 & 0.0001 & 0.849 & $.787-.972$ & $4.1-22.6$ \\
\hline
\end{tabular}

Fuente: Elaboración propia con base en el MCS de la ENIGH 2010.

Cuadro 6. Medidas para la determinación del número óptimo de clases latentes, 2012

\begin{tabular}{ccccccc}
\hline \multicolumn{7}{c}{ Lo-Mendell-Rubin LRT Test } \\
\cline { 3 - 4 } Clases & BIC ajustado & Valor & Valor de P & Entropía & $\begin{array}{c}\text { Probabilidades de } \\
\text { Clasificación correcta } \\
\text { (rango) }\end{array}$ & $\begin{array}{c}\text { Porcentaje en la } \\
\text { Clase (rango) }\end{array}$ \\
\hline 2 & -120555 & 31572 & 0.0001 & 0.776 & $.916-9.46$ & $36.3-63.7$ \\
3 & -139350 & 18263 & 0.0001 & 0.811 & $.867-.924$ & $15.6-55.7$ \\
4 & -151726 & 15532 & 0.0001 & 0.839 & $.898-.948$ & $8.8-42.4$ \\
5 & -156902 & 5047 & 0.0001 & 0.835 & $.846-.945$ & $7.5-31.8$ \\
6 & -161171 & 4165 & 0.0001 & 0.875 & $.871-.968$ & $7.2-27.6$ \\
7 & -162733 & 1539 & 0.0001 & 0.813 & $.765-.944$ & $3.4-23.4$ \\
\hline
\end{tabular}

Fuente: Elaboración propia con base en el MCS de la ENIGH 2012.

Con base en estas medidas, se puede concluir que el número óptimo de clases para clasificar el grado de confianza es 4 para los tres años. En los gráfi$\cos 2,3$ y 4 se muestran las proporciones de los factores asociados a redes de dinero y tiempo según la clase a la que pertenece. Es importante recordar que el grado de confianza clasifica a los hogares, por lo tanto, todas las personas 
pertenecientes a un hogar comparten la misma clase, es decir, el mismo grado de confianza. Los puntajes de los factores son menores en la clase 1 que en la clase 2; los de la clase 2 son menores que los de la clase 3, y los de la clase 3 son menores que los de la clase 4 . La clase 4 es la de mejor o mayor percepción sobre su acceso a los favores/ayudas. Dicho de otra forma, es la clase de hogares con mayor grado de confianza. En contraste, la clase de hogares 1 es la que goza de menor grado de confianza.

Gráfico 2. Factores de dinero y tiempo, 2008

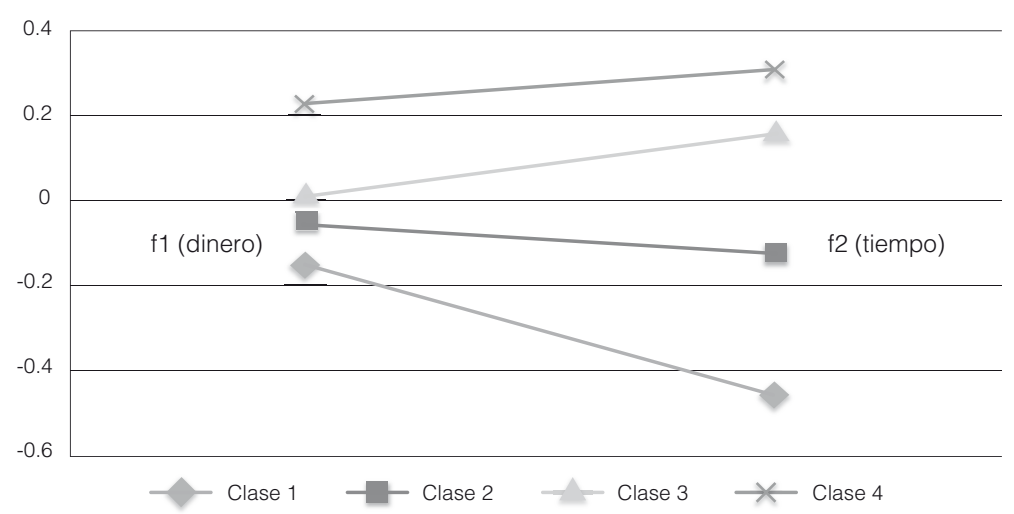

Fuente: Elaboración propia con base en el MCS de la ENIGH 2008.

Grafico 3. Factores de dinero y tiempo, 2010

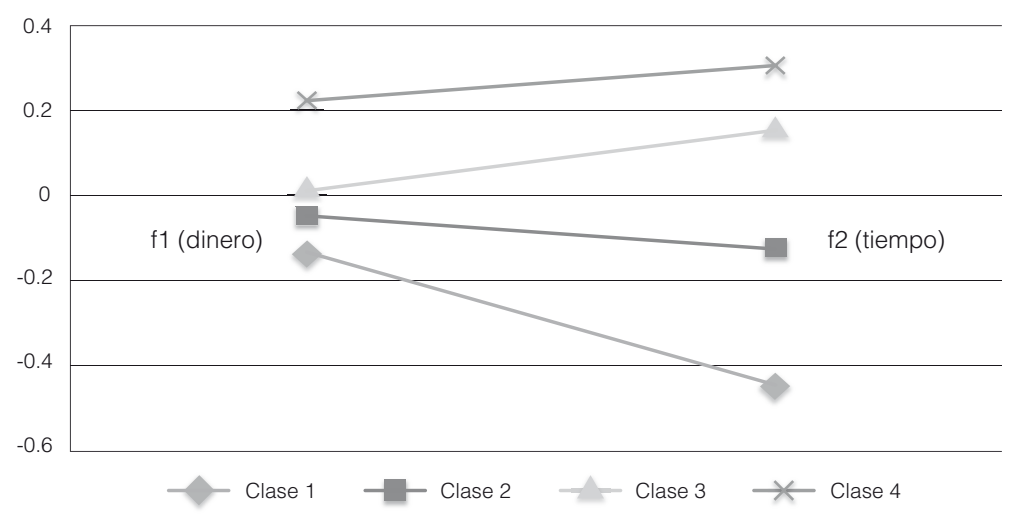

Fuente: Elaboración propia con base en el MCS de la ENIGH 2010. 
Gráfico 4. Factores de dinero y tiempo, 2012

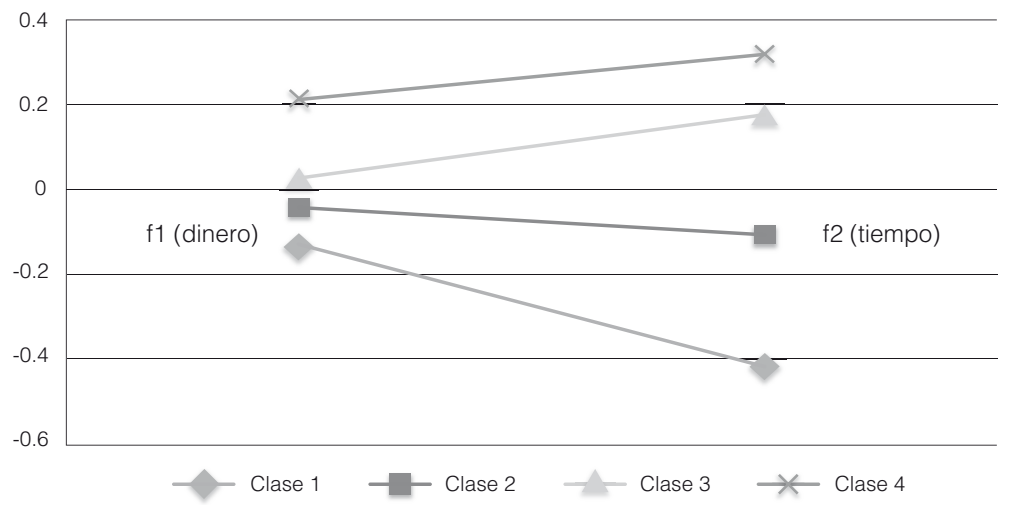

Fuente: Elaboración propia con base en el MCS de la ENIGH 2012.

Clasificación de los hogares del país según su grado de confianza 2008, 2010, 2012

El propósito de generar una clasificación sobre el grado de confianza con el que cuentan los hogares para recibir distintos tipos de ayuda es determinar qué tipo de características tienen las personas que conforman estos hogares y cómo se diferencian de los otros grupos.

\section{Grado de confianza e indicadores asociados a la pobreza}

¿Cuál es la relación de ciertos indicadores asociados a la pobreza con el grado de confianza de las personas? Un análisis previo mostró que existe una relación estrecha entre la percepción de acceso a distintos tipos de favores y los indicadores sociales y económicos que determinan si una persona es pobre $\mathrm{o}$ no (González de la Rocha, Moreno \& Escobar, 2012).

La medición oficial de la pobreza en México es multidimensional y considera que una persona es pobre si su ingreso se encuentra por debajo de la línea de bienestar (que corresponde a la suma de los valores de la canasta alimentaria más la canasta no alimentaria) y cuenta con al menos una carencia social. Las carencias sociales responden a carencias en derechos sociales establecidos en la Ley General de Desarrollo Social (LGDS): educación, acceso a servicios de salud, acceso a la seguridad social, calidad y espacios de la vivienda, servicios básicos en la 
vivienda y acceso a la alimentación. Una persona es pobre extrema si su ingreso se encuentra por debajo de la línea de bienestar mínimo (que corresponde al valor de la canasta alimentaria) y cuenta con al menos tres carencias sociales.

En el cuadro 7 podemos observar cómo se distribuye la población a lo largo del periodo comprendido entre 2008 y 2012 de acuerdo a su grado de confianza en el acceso a los favores. Dado que la estimación del grado de confianza es de corte transversal no es correcto hacer una comparación a través del tiempo, pues el grado de confianza en cada año depende de la distribución para dicho año de las seis preguntas sobre redes sociales.

Cuadro 7. Porcentaje de personas según grado de confianza, 2008-2012

\begin{tabular}{lccc}
\hline Grado & 2008 & 2010 & 2012 \\
\hline Muy baja & 15.5 & 14.9 & 13.2 \\
Baja & 32.0 & 32.6 & 33.6 \\
Media & 44.2 & 44.4 & 45.7 \\
Alta & 8.4 & 8.1 & 7.5 \\
\hline Fuente: Elaboración propia con base en los MCS de la ENIGH 2008, 2010 y 2012.
\end{tabular}

Gráfico 5. Porcentaje de carencias según grado de confianza, 2008

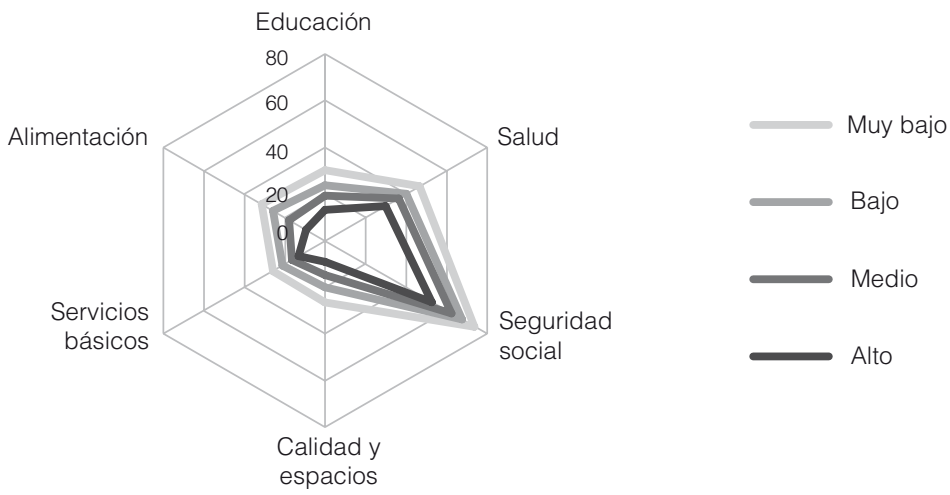

Fuente: Elaboración propia con base en el MCS de la ENIGH 2008.

En los gráficos 5, 6 y 7 se observa el porcentaje de personas con cada una de las carencias sociales. Resulta importante notar dos cosas. Primero, que el grado de confianza en redes sociales y el porcentaje de las carencias están correlacionados. Las carencias siempre están más acentuadas en los grados bajos de 
confianza. Esto habla de una relación inversamente proporcional entre el nivel de carencias y el nivel de confianza que reportan las personas: a mayor grado de confianza, menor porcentaje de carencias. Segundo, que si bien a lo largo de los tres ańos se observa la misma relación, las brechas para 2008 entre grado de confianza son más acentuadas que las de 2010, y lo mismo sucede entre 2010 y 2012. Este efecto puede deberse a una disminución en general de las carencias sociales de 2008 a 2012, un cambio en el grado de confianza a través de los años, o bien, una combinación de ambas.

Grafico 6. Porcentaje de carencias según grado de confianza, 2010

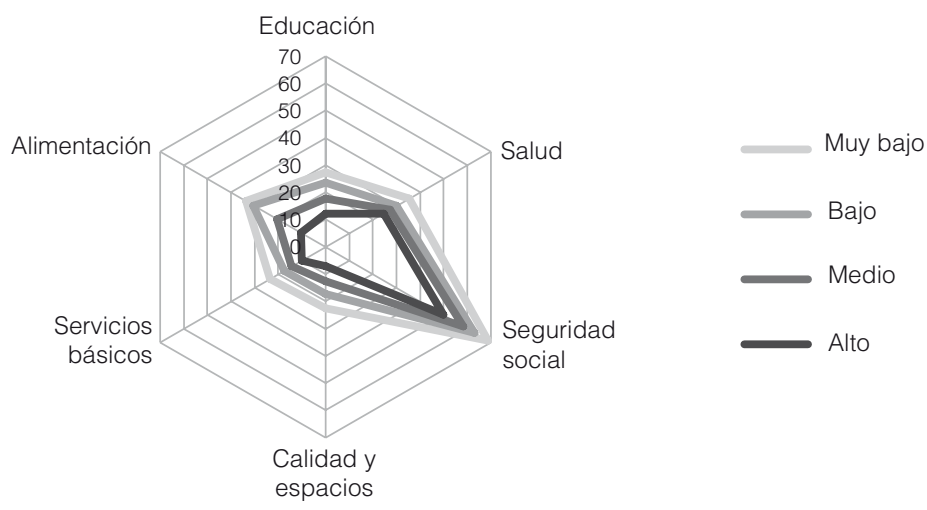

Fuente: Elaboración propia con base en el MCS de la ENIGH 2010.

Grafico 7. Porcentaje de carencias según grado de confianza, 2012

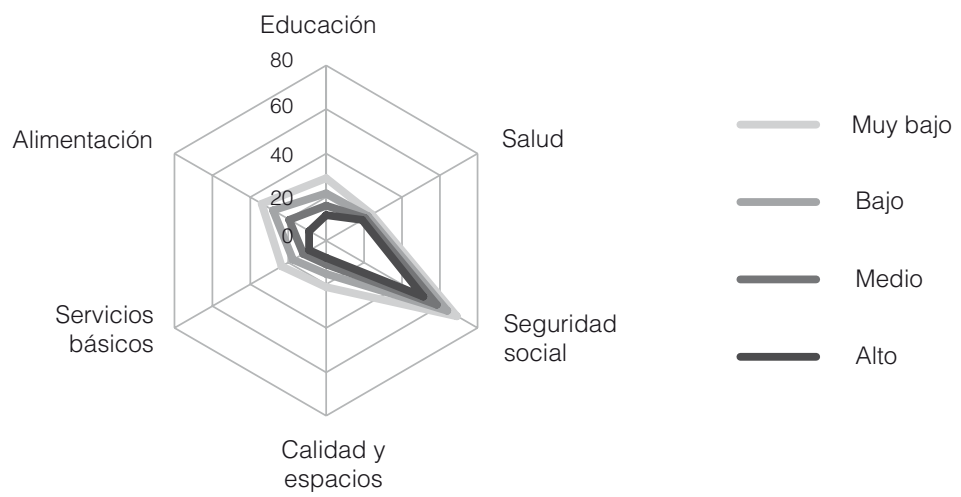

Fuente: Elaboración propia con base en el MCS de la ENIGH 2012.

M. González de la Rocha, M. Moreno Pérez, I. Escobar | Empleo e intercambio social en México Perfiles Latinoamericanos, 24(47) | FLACso México | pp. 225-258 | DoI: 10.18504/pl2447-012-2016 
La pobreza es un fenómeno de carácter multidimensional. No obstante, consideramos que el ingreso es extremadamente importante. Como esperábamos, el grado de confianza guarda también una relación con el ingreso de las personas porque la pérdida de éste modifica las dinámicas económicas y sociales del hogar. Los gráficos 8, 9 y 10 muestran el nivel de ingreso corriente total y el ingreso laboral per cápita a pesos de agosto de cada año, según el nivel de confianza con el que cuentan las personas. Se observa que a mayor grado de confianza en redes sociales, el ingreso aumenta. Sin embargo, se muestra un aumento mayor cuando el grado de confianza es alto.

Gráfico 8. Ingreso per cápita según grado de confianza, 2008

Ingreso corriente

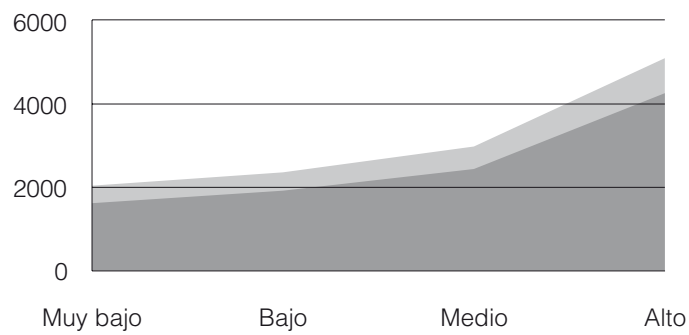

Fuente: Elaboración propia con base en el MCS de la ENIGH 2008.

Gráfico 9. Ingreso per cápita según grado de confianza, 2010

Ingreso corriente

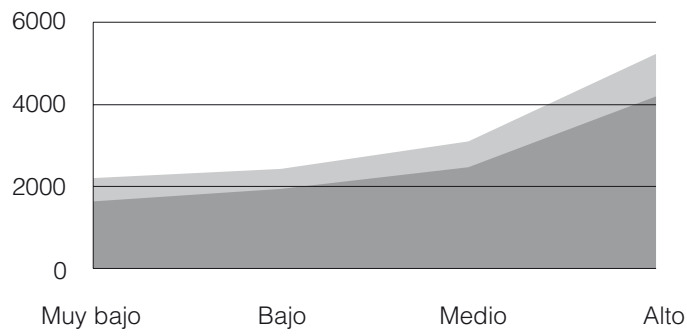

Fuente: Elaboración propia con base en el MCS de la ENIGH 2010. 
Gráfico 10. Ingreso per cápita según grado de confianza, 2012

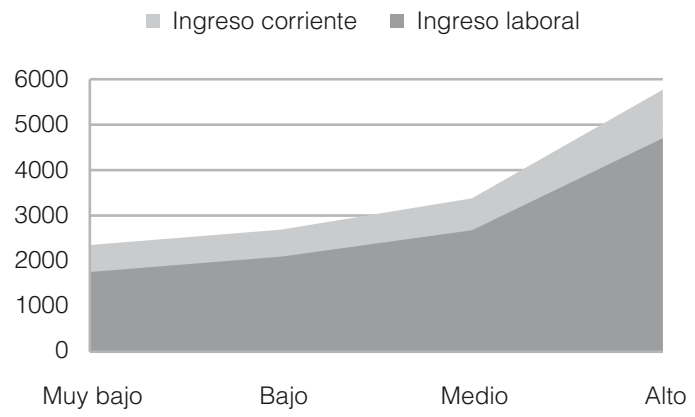

Fuente: Elaboración propia con base en el MCS de la ENIGH 2012.

Analizados los indicadores de carencias sociales e ingreso por separado, lo que resta es averiguar la relación entre el nivel de pobreza y el grado de confianza. El análisis indica que a menor pobreza el grado de confianza aumenta. Este comportamiento se observa para los tres tipos de pobreza, la total, la moderada y la extrema. Sin embargo, parece haber menores saltos, dependiendo del grado de confianza, para los denominados pobres moderados, es decir aquellas personas que no son pobres extremos, pero son pobres.

Gráfico 11. Porcentaje de pobreza según grado de confianza, 2008

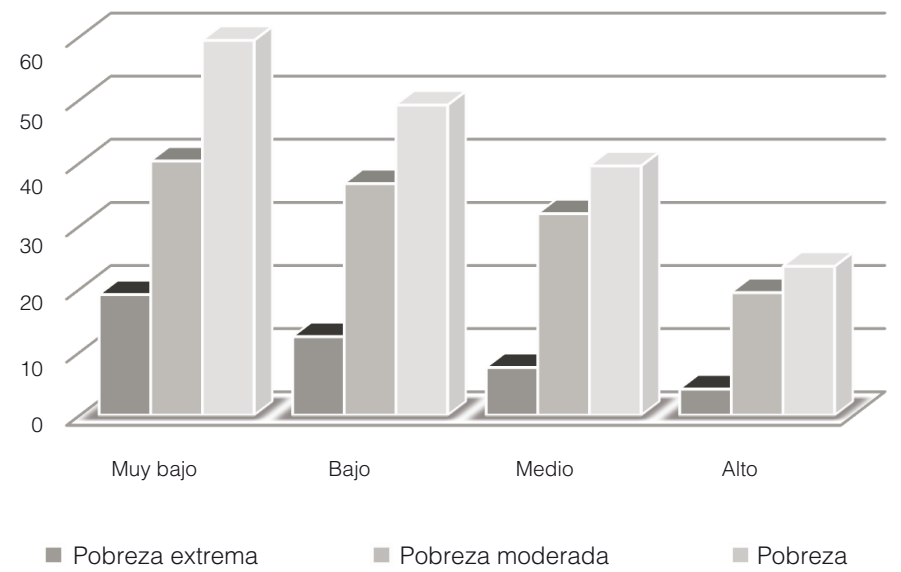

Fuente: Elaboración propia con base en el MCS de la ENIGH 2008.

M. González de la Rocha, M. Moreno Pérez, I. Escobar | Empleo e intercambio social en México Perfiles Latinoamericanos, 24(47) | FLACso México | pp. 225-258 | DoI: 10.18504/pl2447-012-2016 
Gráfico 12. Porcentaje de pobreza según grado de confianza, 2010

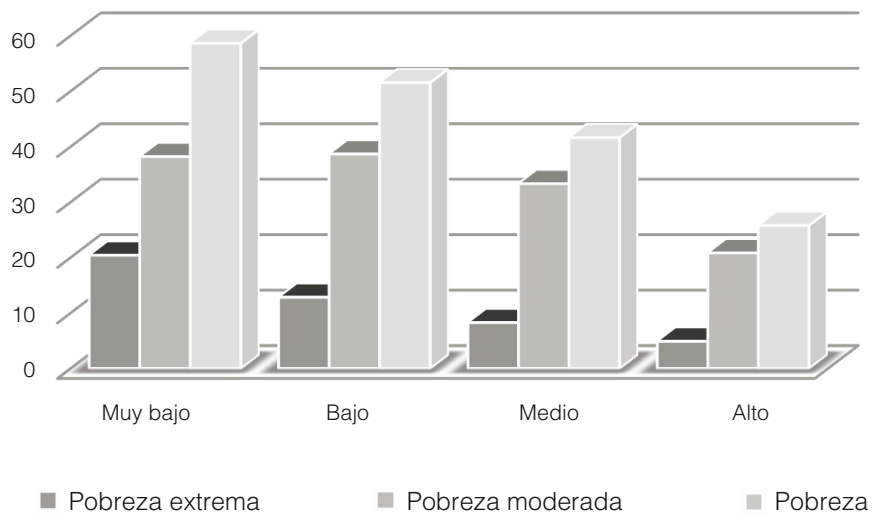

Fuente: Elaboración propia con base en el MCS de la ENIGH 2010.

Gráfico 13. Porcentaje de pobreza según grado de confianza, 2012

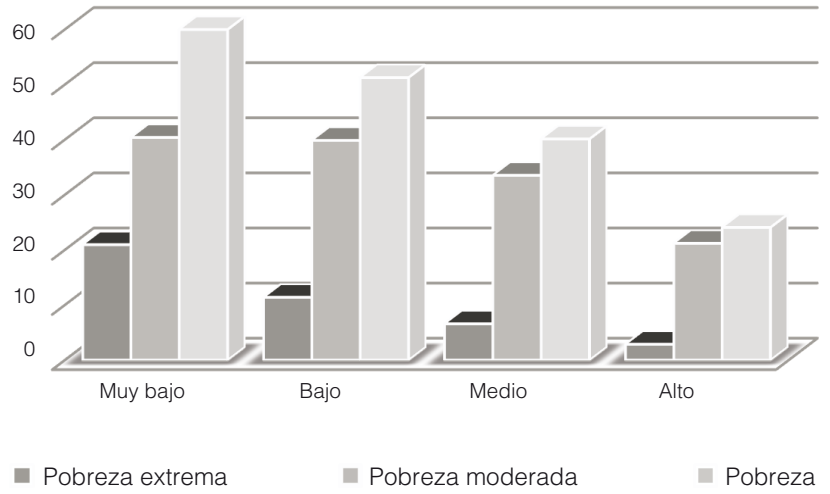

Fuente: Elaboración propia con base en el MCS de la ENIGH 2012.

\section{Grado de confianza y empleo}

Una de las principales problemáticas que llevan a la reproducción de la pobreza es la falta de empleos que brindan seguridad social. Ésta ampara al trabajador y a su familia ante eventualidades tales como accidentes o enfermedades, o ante eventos propios del ciclo de vida como la vejez y el embarazo (CONEVAL, 2010). Los empleos precarios causan pobreza y erosionan la capacidad de cons- 
truir y mantener vínculos y redes sociales. En la sección que sigue se analiza la relación entre precariedad y el grado de confianza.

No existe consenso sobre el número y tipo de prestaciones laborales que debe tener un trabajador para ser considerado "cubierto" en cuanto a seguridad social, pero las prestaciones mínimas que se consideran para medir la pobreza son los servicios médicos, la incapacidad con goce de sueldo en caso de accidente, enfermedad o maternidad y el acceso a un sistema de jubilaciones o pensiones para el retiro (CONEval, 2010). Decidimos, con el propósito de observar las diferencias entre los trabajadores según su grado de confianza y sus prestaciones laborales, utilizar otras prestaciones además de las mencionadas. Se consideraron: servicio médico, contrato, incapacidad médica con goce de sueldo, aguinaldo, pensión por invalidez y SAR o Afore.

En el gráfico 14 se presenta el número promedio de prestaciones laborales con las que cuentan los trabajadores, desde 2008 hasta 2012, según el grado de confianza en redes sociales.

El análisis corrobora las hipótesis planteadas. El grado de confianza en recibir ayuda se encuentra relacionado con las prestaciones laborales. Los trabajadores con más prestaciones son los que tienen más confianza en recibir favores. Lo preocupante es que, en promedio, los trabajadores que se encuentran en la mejor situación, es decir aquellos cuyo grado de confianza es alto, no alcanzan ni siquiera 2.5 prestaciones de las seis que se están considerando. Si se examina al total de los trabajadores, independientemente de su grado de confianza, el promedio de prestaciones laborales es de 1.8 para los tres años.

Gráfico 14. Número promedio de prestaciones según grado de confianza, 2008-2012

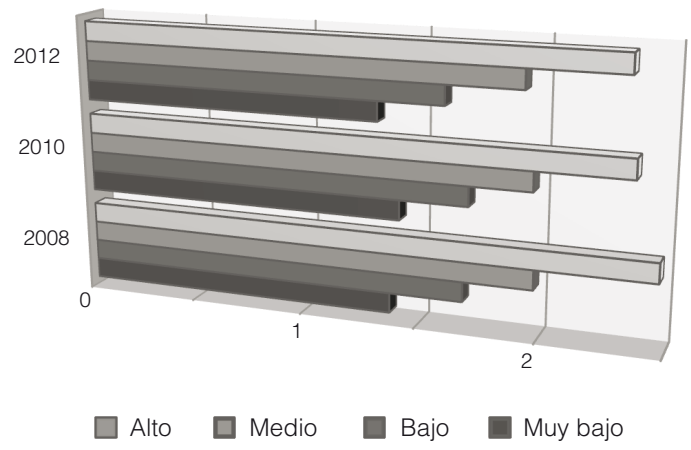

Fuente: Elaboración propia con base en los MCS de las ENIGH 2008, 2010 y 2012. 
Al clasificar a los trabajadores en aquellos que cuentan con buenos o malos empleos de conformidad con el número de prestaciones laborales que tienen, considerando como un buen empleo aquél que ofrezca las seis prestaciones laborales arriba citadas, y un mal empleo el del trabajador a quien le falta al menos una de ellas, sólo alrededor del $12 \%$ de los trabajadores cuentan con un buen empleo en los tres años. Sin embargo, en el gráfico 15 se observa el comportamiento diferenciado entre clases. Los trabajadores con buenos empleos que tienen muy bajo grado de confianza no alcanzan a ser ni el 10\%, mientras que aquellos con alto grado de confianza se encuentran para los tres años por arriba del 17 por ciento.

Gráfico 15. Porcentaje de empleos buenos según grado de confianza, 2008-2012

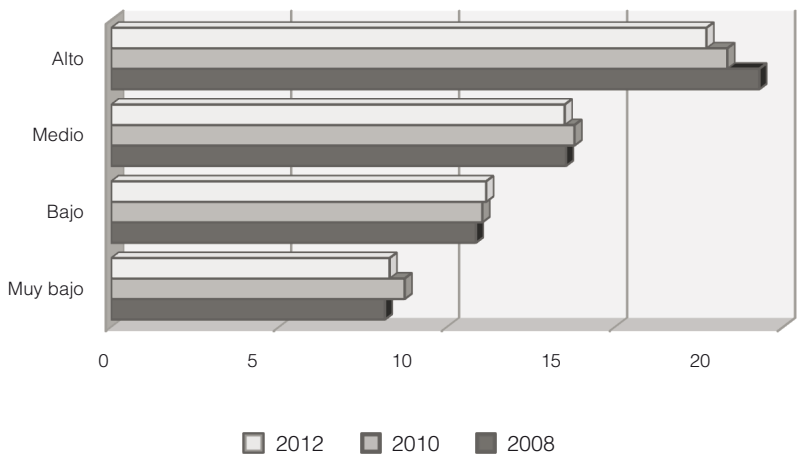

Fuente: Elaboración propia con base en los MCS de las ENIGH 2008, 2010 y 2012.

Para analizar la relación entre el grado de confianza que reportan las personas en los hogares y el nivel de ingreso laboral que tienen, se construyeron quintiles de ingreso laboral per cápita por hogar. Veremos cuántos hogares caen en cada quintil dependiendo de si los integrantes del hogar tienen un grado muy bajo o alto de confianza. Los resultados se presentan en los gráficos 16, 17 y 18.

Para los hogares con grado de confianza alto, el porcentaje mayor se presenta en el quintil con mayores ingresos, mientras que para los hogares con grado de confianza muy bajo pasa lo contrario, el mayor porcentaje se concentra en el quintil con menores ingresos laborales.

Nuestros hallazgos indican que las personas cuyos hogares registran mayores grados de confianza tienden a gozar de mejores condiciones laborales, no sólo en el número y tipo de prestaciones laborales sino, también, en el ingreso que obtienen de su empleo. 
Gráficos 16. Porcentaje de hogares en cada quintil de ingreso laboral per cápita según grado de confianza, 2008

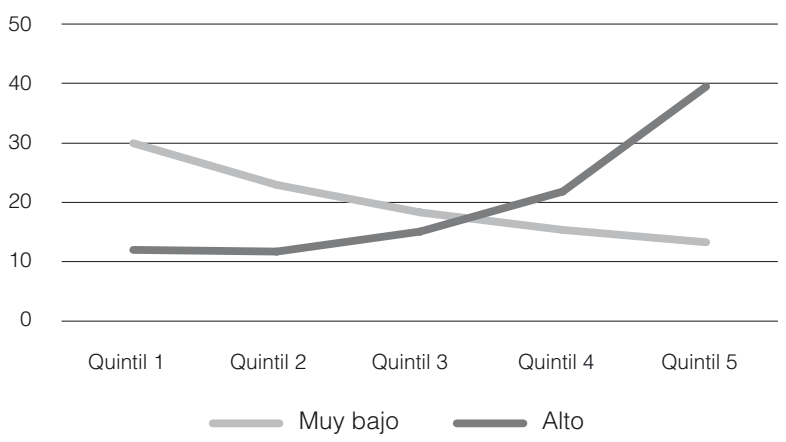

Fuente: Elaboración propia con base en el MCS de la ENIGH 2008.

Gráfico 17. Porcentaje de hogares en cada quintil de ingreso laboral per cápita según grado de confianza, 2010

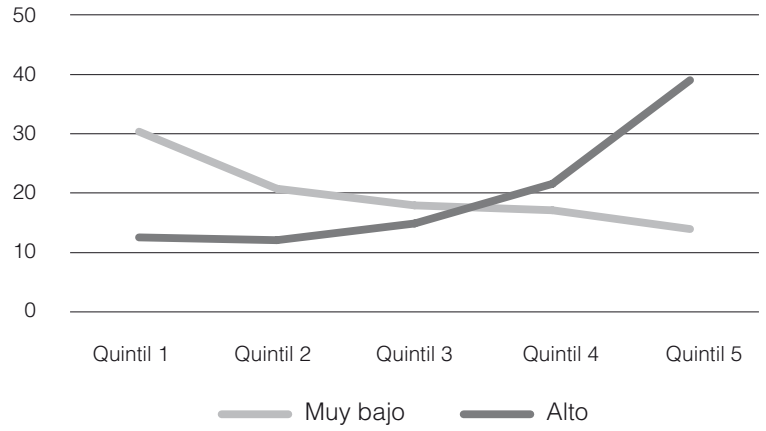

Fuente: Elaboración propia con base en el MCS de la ENIGH 2010.

Gráfico 18. Porcentaje de hogares en cada quintil de ingreso laboral per cápita según grado de confianza, 2012

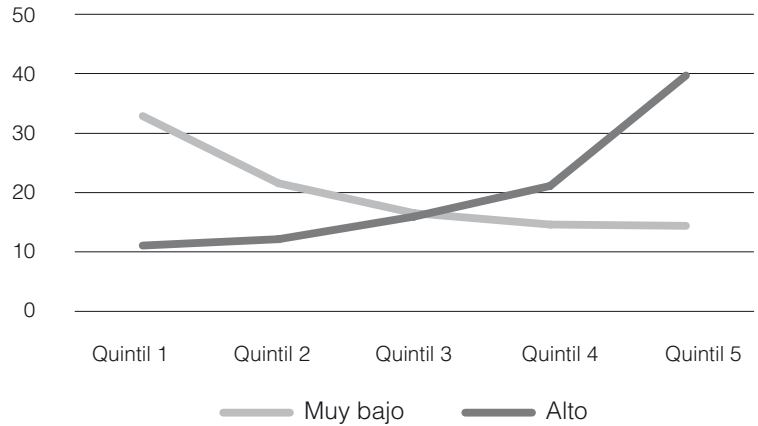

Fuente: Elaboración propia con base en el MCS de la ENIGH 2012.

M. González de la Rocha, M. Moreno Pérez, I. Escobar | Empleo e intercambio social en México 


\section{Conclusiones}

La pérdida de confianza es una realidad en el México contemporáneo. Los mexicanos hemos dejado de confiar en las distintas instancias de gobierno y en los partidos políticos, en la policía y en los líderes comunitarios. La parentela - en concreto la familia - parece ser uno de los últimos reductos de solidaridad donde la confianza sigue alimentando las relaciones y haciendo posible el flujo de favores. ${ }^{11}$ Los vecinos cercanos y los amigos también han formado parte de las redes de apoyo donde la confianza y la reciprocidad dictan el vaivén de los bienes y servicios, o las permutas de favores en cadenas de intercambios. Sin embargo, como hemos mostrado en este análisis, estos flujos se ven amenazados en contextos de pobreza, bajos ingresos y precariedad del empleo. El acceso a las redes sociales de apoyo no es homogéneo (algo a lo que todo el mundo pueda acceder sin diferencias ni dificultades), sino altamente diferencial y particularmente sensible a los ingresos y a la calidad del empleo.

Este artículo es el resultado de un mestizaje disciplinario. Hallazgos etnográficos relativos al aislamiento social como producto de la pobreza y la precariedad laboral fueron puestos a prueba y corroborados a través de técnicas estadísticas de elevada precisión. El análisis mostró que la relación entre pobreza, calidad del empleo y acceso a los favores/ayuda existe, que el empleo seguro y protegido afianza el acceso a redes sociales de apoyo y que la precariedad laboral deteriora los vínculos sociales. Encontramos que los dos recursos clave para que las personas participen en redes sociales de apoyo son el tiempo y el dinero. El uso de uno u otro recurso para el canje de favores lleva a posibilidades distintas de intercambio social. Se observaron patrones que indican la existencia de dos distintos circuitos o esferas de intercambio: uno que tiene que ver con el dinero y otro cuya lógica está dictada por el tiempo. El uso de dinero como instrumento para dar $\mathrm{u}$ ofrecer favores se lleva a cabo en un tipo de intercambio que es distinto al que fluye con el recurso tiempo. Aunque hay personas que participan más en uno u otro circuito, todas pueden acceder a ambos en tanto usen, por decirlo así, la moneda correcta. Se trata de circuitos distintos porque las monedas no pueden ser intercambiadas, no sin complejidades. Los bienes que circulan en el circuito del dinero no pueden ser movilizados con la moneda tiempo. En el circuito del tiempo la moneda dinero no opera; se trata básicamente de intercambio de provisión de cuidados. Como en el caso de los circuitos Tiv estudiados por Bohannan (1955), se podría esperar que el intercambio de las categorías de bienes y las categorías de "monedas" que circulan en estos

11 El otro reducto es la iglesia, según la mayoría de las encuestas. 
dos circuitos exclusivos sea posible sólo mediante la negociación de normas y principios morales, porque cada uno de los circuitos y de los bienes están marcados por distintas y separadas actitudes (cargas) morales. Por ejemplo, se espera que una madre anciana reciba los cuidados de sus hijos, aunque técnicamente estos cuidados puedan ser adquiridos con dinero mediante atención o custodia institucional. Pero es necesario negociar o de plano transgredir las normas y principios morales que rigen las obligaciones de los hijos para canjear el tiempo (dedicado a los cuidados) por el dinero (pago de custodia institucional). La hermana, vecina o amiga enferma espera que se le acompañe al doctor, no que se contraten los servicios de una dama de compañía.

El circuito del tiempo es más socorrido que el circuito del dinero. Las personas tienen más fácil acceso a los miembros de sus redes para ser acompañadas al doctor, el cuidado de niños y para cuidados en casos de enfermedad. Menos facilidad de acceso a redes sociales de apoyo se declara para fines económicos: los préstamos de dinero y las cooperaciones para mejorar del entorno. Es decir, los problemas de salud y las tareas de cuidado despiertan mayor empatía que los asuntos que se contabilizan en pesos y centavos. Es también posible que para la mayoría de las personas sea más fácil ayudar con tiempo que con dinero. Es un hecho, sin embargo, que mientras más ingresos se tienen mayor es el acceso a redes sociales "económicas" o, dicho de otra manera, se reciben y se dan más préstamos de dinero. Existe una relación positiva entre empleos estables que brindan protección al trabajador y a su familia y el acceso al intercambio social en ambos tipos de circuitos. En conclusión, existe una fuerte correlación entre el grado de confianza en el acceso al intercambio social y los buenos empleos, es decir, los empleos que además de un ingreso proporcionan prestaciones sociales.

La importancia de nuestros hallazgos para la comprensión del intercambio social es indiscutible, así como incuestionable es la centralidad del empleo - y del buen empleo- en el bienestar de los trabajadores y sus familias. Aunque no es posible hablar de una relación de causalidad unidireccional, sabemos que el acceso al intercambio social y el acceso a mejores empleos están relacionados y que ambos se retroalimentan y refuerzan. El análisis de los múltiples factores que condicionan el acceso a las redes sociales no está agotado y seguiremos profundizando en ello mediante técnicas específicas tanto estadísticas como etnográficas.

Nuestros hallazgos aportan elementos para el conocimiento de fenómenos más amplios que los que se observan en los microcosmos sociales, porque las relaciones cotidianas de solidaridad son de enorme importancia para la creación y mantenimiento del tejido social más amplio. Como plantean Pahl y Spencer (1997), la "comunidad", la "cohesión social”, no están apartadas de las dinámicas sociales; están conformadas por pequeños conjuntos de relaciones 
sociales, de vínculos que la gente construye y, a través de éstos, moldea sus propias identidades y sentidos de pertenencia. Trabajar hacia una sociedad más solidaria y amable, con más lazos de amistad, confianza y reciprocidad entre los individuos que la componen implica tomar en cuenta a la gente misma, en sus barrios, en sus empleos y en sus hogares, donde de hecho están, en donde viven y en las formas en que trabajan. Se puede estar seguro de que a mayor desprotección en el empleo habrá más obstáculos para la ayuda y cooperación mutua, elementos que sin duda forman parte de los procesos de deterioro de la unidad o cohesión social.

\section{Referencias}

Arias, P. (1988). El empleo a domicilio en el medio rural: la nueva manufactura. Estudios Sociológicos, 6(8), 535-552.

Arias, P. \& Bazán, L. (1980). C.I.V.A.C. un proceso de industrialización en una zona campesina (2a. edición). México: CISINAH.

Banco Mundial. (2012). World Development Report 2013. Jobs, Washington, D.C.: The World Bank.

Bazán, L. (1999). Cuando una puerta se cierra cientos se abren. Casa y familia: los recursos de los desempleados de la refinería 18 de Marzo. México: CIESAS.

Benería, L. \& Roldán, M. (1987). The Cross Roads of Class and Gender. Industrial homework, subcontracting, and household dynamics in Mexico City. Chicago: University of Chicago Press.

Bentler, P. M. (1990). Comparative Fit Indexes in Structural Models. Psychological Bulletin, 107(2), 238-246.

Bohannan, P. (1955). Some Principles of Exchange and Investment among the Tiev. American Anthropologist, New Series, 57(1), 60-70.

Bourdieu, P. (1984). Distinction: A Social Critique of the Judgement of Taste. Cambridge, Massachusetts: Harvard University Press.

Bourguignon, F. (2005). Development Strategies for More and Better Jobs. Documento presentado en la Help Wanted: More and Better Jobs in a Globalized Economy Conference, Washington, D.C., Carnegy Endowment of International Peace, 14 y 15 de abril. 
Brown, T. A. (2006). Confirmatory Factor Analysis for Applied Research. Nueva York: The Guilford Press.

Consejo Nacional de Evaluación de la Política de Desarrollo Social (coneval). (2010). Metodología para la medición multidimensional de la pobreza en México. México: coneval.

Escobar Latapí, A. (1986). Con el sudor de tu frente. Mercado de trabajo y clase obrera en Guadalajara. Guadalajara: El Colegio de Jalisco.

Estrada, M. (1996). Después del despido. Desocupación y familia obrera. México: Ciesas.

Fernández-Kelly, M. P. (1983). For We Are Sold, I and My People. Women and industry in Mexico's frontier. Albany: State University of New York Press.

García Guzmán, B. (2009). Los mercados de trabajo urbanos de México a principios del siglo xxI. Revista Mexicana de Sociología, 71(9), 5-46.

García, B. \& Oliveira, O. de (1992). Recesión económica y cambios en los determinantes del trabajo femenino. Ciencia, 43(4), 367-380.

García, B., Muñoz, H. \& Oliveira, O. de (1982). Hogares y trabajadores en la Ciudad de México. México: El Colegio de México/unam.

González de la Rocha, M. ([2001] 2015). From the Resources of Poverty to the Poverty of Resources? The Erosion of a Survival Model. En Chant, S. (Ed.), Gender, Poverty and Development, Kew Approaches and Concepts, vol. 1 (pp. 139-165). Reino Unido: Routledge.

González de la Rocha, M. (2000). Private Adjustments: Household Responses to the Erosion of Work. Nueva York: United Nations Development Programme.

González de la Rocha, M. (1999). La reciprocidad amenazada: un costo más de la pobreza urbana. En Enríquez, R. (Coord.), Hogar, pobreza y bienestar en México (pp. 13-36). Guadalajara: Instituto Tecnológico de Estudios Superiores de Occidente.

González de la Rocha, M. (1994). The Resources of Poverty. Women and Survival in a Mexican City. Oxford: Basil Blackwell.

González de la Rocha, M. (1991). Family Well-Being, Food Consumption, and Survival Strategies During Mexico’s Economic Crisis. En González de la Rocha, M. \& Escobar, A. (Eds.), Social Responses to Mexico's Economic Crisis of the 1980's (pp. 115-127). La Jolla: Centro de Estudios México-Estados Unidos, Universidad de California en San Diego. 
González de la Rocha, M. (1986). Los recursos de la pobreza. Familias de bajos ingresos en Guadalajara. Guadalajara: El Colegio de Jalisco/ CIESAs/spp.

González de la Rocha, M., Moreno, M. \& Escobar, I. (2012). Trabajo, modos de subsistencia y vida social en México. Documento elaborado en el proyecto Moving Jobs to the Center Stage in Mexico. Case study for the World Development Report 2013. Versión final, 13 de julio de 2012, mimeo.

González de la Rocha, M. \& Villagómez, P. (2008). ¿Encuesta o etnografía? Avances y tropiezos en el estudio del intercambio social. En Cortés, F., Escobar, A. y González de la Rocha, M., Método cientifico y politica social. A propósito de las evaluaciones cualitativas de programas sociales en México (pp. 297-373). México: El Colegio de México.

González de la Rocha, M. \& Villagómez, P. (2006). Espirales de desventajas: pobreza, ciclo vital y aislamiento social. En Saraví, Gonzalo (Ed.), De la pobreza a la exclusión. Continuidades y rupturas de la cuestión social en América Latina (pp. 137-166). Buenos Aires: CIESAS/ Prometeo.

González de la Rocha, M. \& Escobar, A. (1986). Crisis y adaptación. Hogares de Guadalajara. Tercera Reunión sobre la Investigación Demográfica en México, Sociedad Mexicana de Demografía. México, 3-6 de noviembre.

Hagernaars, J. A. \& McCutheon, A. L. (2002). Applied Latent Class Analysis. Cambridge: Cambridge University Press.

Hale, T. W. (1997). The Working Poor. Monthly Labor Review, 120, 47-48.

Hu, L. \& Bentler, P. M. (1999). Cutoff Criteria for Fit Indexes in Covariance Structure Analysis: Conventional Criteria versus New Alternatives. Structural Equation Modeling, 6(1), 1-55.

Instituto Nacional de Estadística, Geografía e Informática (INEGI). (2005). Encuesta Nacional de Ocupación y Empleo 2005. Una nueva encuesta para México. 50 preguntas y respuestas. Aguascalientes: INEGI.

Jöreskog, K. G. \& Sörbom, D. (1981). Analysis of Linear Structural Relationships by the Method of Maximum Likelihood. Chicago: National Educational Resources (Scientific Software International).

Katungi, D., Neale, E. \& Barbour, A. (2006). People in Low-Paid Informal Work. "Need not Greed". Bristol: The Policy Press.

Kingsolver, A. E. ([1996] 2007). Work. En Barnard A. \& Spenser, J. (Eds.), Encyclopedia of Social and Cultural Anthropology (pp. 847-850). Londres: Routledge. 
Mauss, M. ([1950] 2011). The Gift (12a edición). Abingdon: Routledge.

Moser, C. (1996). Confronting Crisis: A Comparative Study of Household Responses to Poverty and Vulnerability in Four Poor Urban Communities. Washington, D.C.: The World Bank.

Nieto Calleja, R. (1984). Algunas consideraciones sobre antropología y clase obrera en México. En Nolasco, M. (Comp.), La antropología y sus sujetos de estudio. Cuadernos de la Casa Chata 107. México: CIESAS.

Norton, A. \& Haan, A. de (2013). Social Cohesion: Theoretical Debates and Practical Applications with Respect to Jobs. Background paper for the World Development Report 2013. Washington, D.C.: The World Bank.

Nylund, K. L., Asparouhov, T. \& Muthén, B. O. (2007). Deciding on the Number of Classes in Latent Class Analysis and Growth Mixture Modeling: A Monte Carlo Simulation Study. En Structural Equation Modeling: A Multidisciplinary Journal, volumen 14 (Cuarta edición) (pp. 535-569). Routledge. Recuperado de http://www.tandfonline.com/toc/hsem20/14/4

Novelo, V. (1980). De huelgas, movilizaciones y otras acciones de los mineros del carbón en Coahuila. Revista Mexicana de Sociología, XLII(4), 1355-1377.

Pahl, R. E. (1991). The Search for Social Cohesion: From Durkheim to the European Comission. European Journal of Sociology, 32(2), 345-360.

Pahl, R. E. (1984). Divisions of Labour. Oxford: Blackwell Publishers.

Pahl, R. \& Spencer, L. (1997, 26 de septiembre). Friends and Neighbours. New Statesman, 36-37.

Pahl, R. E. \& Wallace, C. (1985). Household Work Strategies in Economic Recession. En Redclift, N. \& Mingione, E. (Eds.), Beyond Employment. Household, Gender and Subsistence (pp. 189-227). Oxford: Basil Blackwell.

Peiró, J. M. (1996). Psicología social de las organizaciones. En Álvaro E., J. L. et al. (Coords.), Psicología social aplicada (pp. 155-157). España: McGraw Hill.

Rabell, C. (Coord.). (2009). Tramas familiares. México: El Colegio de México.

Rabell Romero, C. \& D’Aubeterre, M. E. (2009). ¿¿Aislados o solidarios? Ayudas y redes sociales familiares en el México contemporáneo. En Rabell Romero, C. (Coord.), Tramas familiares. México: El Colegio de México.

Ridgon, E. E. (1996). CFI versus RMSEA: A comparison of two fit indexes for structural equation modeling. Structural Equation Modeling, 3(4), 369-379. 
Roberts, B. ([1973] 2011). Organizando extraños: Familias pobres en la ciudad de Guatemala. Guatemala: Flacso Guatemala.

Samuel, R. (1975). Village Life and Labour. Londres: Routledge and Kegan Paul.

Sariego, J. L. (1990). Enclaves y minerales en el norte de México. Historia social de los mineros de Cananea y Nueva Rosita, 1900-1970. México: Ediciones de la Casa Chata-CIESAS.

Standing, G. (2010). Work after Globalization. Londres: Edward Elgar.

Steiger, J. H. \& Lind, J. C. (1980). Statistically based test for the numer of common factors. Ponencia presentada en Annual Metting of the Psychometric Society, Iowa City, IA.

Tokman, V. (2007). The Informal Economy, Insecurity and Social Cohesion in Latin America. International Labour Review, 146(1-2), 81-107.

Wallerstein, I., Martin, W. G. \& Dickinson, T. (1982, invierno). Household structures and production processes: preliminary theses and findings. Review. A Journal of the Fernand Braudel Centre for the Study of Economies, Historical Systems and Civilizations, 3, 437-458.

\section{Encuestas}

Módulos de Condiciones Socioeconómicas de la Encuesta Nacional de Ingresos y Gastos de los Hogares (MCS/ENIGH) 2008, 2010, 2012.

Recibido el 27 de mayo de 2015. Aceptado el 21 de agosto de 2015. 